\title{
Cardiac stem cell therapy: Does a newborn infant's heart have infinite potential for stem cell therapy?
}

Shunji Sano, MD, PhD, ${ }^{\mathrm{a}}$ Toshikazu Sano, MD, PhD, ${ }^{\mathrm{a}}$ Shuta Ishigami, MD, PhD, ${ }^{\mathrm{a}}$ and Tatsuo Ito, MD, $\mathrm{PhD}^{\mathrm{b}}$

Feature Editor's Introduction-The recent decade has witnessed unprecedented research activity in the field of myocardial regeneration with particular enthusiasm displayed around cardiac stem cell therapy. This enthusiastic research resulted in a number of clinical studies, in which cardiac progenitor cells were delivered to the myocardium during heart surgery in children and adults, demonstrating improvement in heart function. The stem cell therapy appeared to be of great promise in children, particularly neonates, who are likely to have higher regenerative potential. A fascinating and groundbreaking study was recently published in Nature, and is discussed below, demonstrating that injection of live or dead cardiac progenitor cells, live or dead mononuclear cells, or zymosan-a nonspecific inducer of inflammation obtained from baker's yeast-into the heart resulted in activation of innate immunity and sustained improvement of cardiac function. No new cardiomyocytes were generated. This beneficial effect was abrogated by immune-suppression or macrophage blockade, suggesting that immune activation is necessary to improve cardiac function. If sustained improvement of cardiac function can equally be obtained by the substance coming from dead cardiac progenitor cells or from baker's yeast, should we continue to refine stem cell therapy or focus on nonexpensive ways to induce acute immune response? Could injection of tomato juice instead of cardiac progenitor cells provide the same end result? It is now becoming increasingly clear that the immune system plays a key role in regeneration of an injured heart. Where to from here? Below is a feature article produced by Shunji Sano, the world's leading expert in clinical application of cardiac stem cell therapy, and his team discussing the current state of stem cell therapy for a newborn infant's heart. The feature article and accompanying commentaries provide stimulating reading for inquisitive surgical minds.

From the a Division of Pediatric Cardiothoracic Surgery, Department of Surgery, University of California, San Francisco, San Francisco, Calif; and ${ }^{\mathrm{b}}$ Department of Hygiene, Kawasaki Medical University, Okayama, Japan.

Received for publication April 26, 2020; revisions received July 17, 2020; accepted for publication July 29, 2020; available ahead of print Sept 14, 2020.

Address for reprints: Shunji Sano, MD, PhD, Division of Pediatric Cardiothoracic Surgery, Department of Surgery, University of California, San Francisco, 550 16th St, Floor 5 Pediatric CT Surgery, San Francisco, CA 94143-0117 (E-mail: Shunji.sano@ucsf.edu).

J Thorac Cardiovasc Surg 2022;163:242-7

$0022-5223 / \$ 36.00$

Copyright (c) 2020 by The American Association for Thoracic Surgery

https://doi.org/10.1016/j.jtcvs.2020.07.124

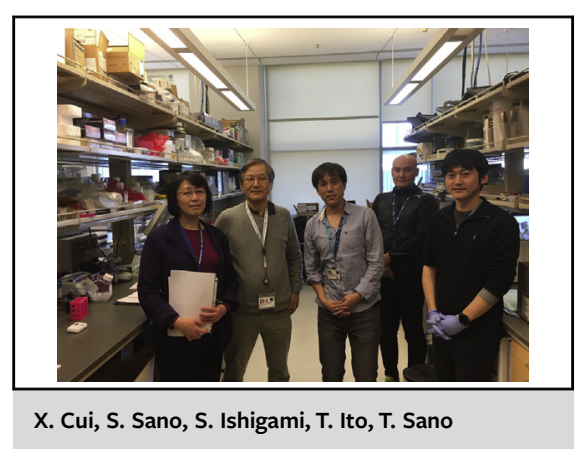

\section{CENTRAL MESSAGE \\ A newborn infant's heart has an infinite potential for stem cell therapy and neonates might be the best candidates for stem cell therapy.}

This Invited Expert Opinion provides a perspec tive on the following paper: Nature. 2020; 577(7790):405-409. https://doi.org/10.1038/s41586 019-1802-2.

See Commentaries on pages 248 and 249.

\section{Igor E. Konstantinov, MD, PhD, FRACS}

For the past 2 decades, stem cell therapies have emerged as among the most highly investigated treatments for cardiovascular disease. A majority of the preclinical and clinical research in stem cell therapy for heart disease has been focused on the recovery or regeneration of ischemic myocardium in adult patients. ${ }^{1-3}$ Several stem cell populations from people of different ages (neonate to adult) and from different tissues (noncardiac or cardiac) are under active investigation. Nonembryonic stem cells have been found in the bone marrow, peripheral blood, adipose tissue, skeletal muscle, umbilical cord blood (UCB), and cardiac tissue. As shown in Table 1, various types of stem cells have been used for cell therapy in cases of ischemic heart disease and heart failure (HF). ${ }^{4}$ Several routes of delivery of stem cells, including intracoronary, intramyocardial, and intravenous, are applied to the heart. Initial systemic reviews and meta-analysis related to stem 
cell therapy for HF and acute myocardial infarction (AMI) have revealed the benefit of cell therapies for cardiac function, exercise tolerance, and quality of life in adult populations. $^{2}$

The discovery of endogenous cardiac progenitor cells (CPCs) and cardiosphere-derived cells (CDCs) is among the exciting new technologies in the field of cardiac regeneration, which has yielded much interest relating to their proliferative and differentiation potentials. Several investigators have revealed resident populations of CPCs in postnatal human hearts. ${ }^{5,6}$ The term c-kit+ CPCs refers to a multipotent cell population expressing the tyrosine kinase receptor c-kit. They are believed to be a primary source for the generation of new myocardium in the setting of myocardial injury. CDCs, derived from the mesenchymal component of heart tissue, have been found to possess a multipotent ability. CDCs consist of a heterogeneous cell population and unlike c-kit+ CPCs, CDCs do not require cell sorting. The heart tissue from which CDCs can be isolated and expanded is typically obtained by endomyocardial biopsy, but may also be collected during open cardiac surgery. CDCs have been shown to exert a greater functional benefit in experimental MI with respect to their remarkable potential for myogenic differentiation, angiogenesis, and paracrine factor secretion compared with other cell types. Based on these results, the first-in-human phase I Food and Drug Administration-approved clinical trial using autologous c-kit $+\mathrm{CPCs}$ in patients with myocardial ischemia commenced in 2009 (the Cardiac Stem Cell Infusion in Patients with Ischemic Cardiomyopathy trial). ${ }^{7}$ The Cardiosphere-Derived Autologous Stem Cells to Reverse Ventricular Dysfunction and Autologous CardiosphereDerived Cells trial was also commenced using autologous CDCs infusion in patients with MI in 2009. ${ }^{8}$ Although many clinical trials are being studied in adult patients with HF and AMI using allogeneic CDCs and autologous cells, most meta-analyses seem to agree that the potential beneficial effect of cell therapies is still inconclusive and statistically underpowered. Furthermore, the recently published global position paper on cardiovascular regenerative medicine stated that, even if cell based therapy in HF patients proved to be safe, the results are neither positive nor consistent and true mechanism of stem cell therapy is still unclear. ${ }^{4,9}$

\section{MECHANISMS OF CARDIOVASCULAR REGENERATIVE RESPONSE}

Somatic stem cells, including cells derived from the heart, bone marrow, adipose tissue, and even circulating nonmyocardial progenitors, are the major cell types that might give rise to cardiomyocytes that in theory could be used in clinical trials. Among the cells described above, CDCs have been shown to exert a greater functional benefit in experimental MI with respect to their remarkable potential for myogenic differentiation, angiogenesis, and paracrine factor secretion compared with other cell types. ${ }^{10}$ Human CDCs could be isolated from right atrial specimens, and resident c-kit-expressing $\mathrm{CPC}$ subpopulation has shown to be the most abundant and proliferative when grown from neonatal CDCs, but this subpopulation declined with age. ${ }^{11}$

A large number of clinical trials have shown stem cell therapy to be a promising therapeutic approach for the treatment of HF; however; the precise underlying mechanisms of action of stem cells are still unclear. Initially, transplanted stem cells were believed to differentiate into cardiomyocytes that integrate with innate myocytes. However, further investigation has revealed that the engraftment rate of transplanted cells was low in the long-term, suggesting a likelihood of insufficient number of differentiated cardiovascular cells to directly replenish the damaged tissue to produce measureable improvement in cardiac function. ${ }^{12}$

TABLE 1. Characteristics of stem cells for cell therapy in the current clinical use

\begin{tabular}{|c|c|c|c|c|}
\hline Type of stem cells & Origin & Characteristic & Advantage & Disadvantage \\
\hline Skeletal myoblasts & Muscles & Unipotent & Easy to harvest & $\begin{array}{l}\text { Low functional integration } \\
\text { between cardiac muscles }\end{array}$ \\
\hline Bone marrow mononuclear cells & Bone marrow & Multipotent & Easy to harvest & No specific to cardiac \\
\hline Mesenchymal stem cells & $\begin{array}{l}\text { Bone marrow } \\
\text { Umbilical cord }\end{array}$ & Multipotent & Easy to harvest & No specific to cardiac \\
\hline Peripheral blood-derived stem cells & Peripheral blood & Multipotent & Easy to harvest & $\begin{array}{l}\text { No specific to cardiac } \\
\text { Low number of cells }\end{array}$ \\
\hline Adipose-derived stem cells & Adipose & Multipotent & Easy to harvest & $\begin{array}{l}\text { No specific to cardiac } \\
\text { Low number of cells }\end{array}$ \\
\hline Umbilical cord blood-derived stem cells & Umbilical cord blood & Multipotent & Easy to harvest & No specific to cardiac \\
\hline Resident cardiac stem cells & Heart tissue & Multipotent & Cardiac cell lineage & Need of cardiac biopsy \\
\hline Embryonic stem cells & Embryo & Multipotent & Multipotency & Ethical concern \\
\hline
\end{tabular}


In addition, the lineage tracing experiments have revealed that vasculogenesis rather than cardiomyogenesis might be an alternative mechanism of action that could be critically involved in the processes of myocardial regeneration. ${ }^{13}$ Experimentally, vasculogenesis may be important in models of chronic coronary occlusion. Clinically, formation of new vessels may contribute to improved cardiac performance in some patients with ischemic heart disease, but it is difficult to imagine how it could do so in the setting of nonischemic cardiomyopathy or in patients with ischemic heart disease.

Recent studies have revealed that stem cell transplantation stimulates endogenous cardiac repair process via paracrine signaling, direct cell to cell interaction, and/or transfer of microRNAs from exosomes that influence the transcriptional activity of host cells. ${ }^{14}$ The important role of exosomes has been highlight as a mechanisms of action after stem cell therapy. Exosomes released from human CDCs were cardioprotective. They inhibited stressinduced cardiomyocyte apoptosis, induced cardiomyocyte proliferation, and stimulated angiogenesis compared with dermal fibroblast-derived exosome in vitro. Exosomes derived from CDC promote angiogenesis, cardiomyocyte survival, and an antifibrotic effect, which is mediated by microRNA transfer.

Although recent evidence suggests that exosomes may act as a vector of genetic information, and messenger RNAs carried by exosomes can be translated into proteins in the target cell, further studies are needed to enhance our understanding of both cellular and molecular mechanisms of cardiac repair with stem cell therapy.

In the issue of an acute immune response underlies the questions of cardiac stem-cell therapy. Vagnozzi and colleagues ${ }^{15}$ tried to disclose the content of acute sterile immune response mainly consisting of the induction of $\mathrm{C}-\mathrm{C}$ chemokine receptor 2 (CCR2)+ and CX3C chemokine receptor $1(\mathrm{CX} 3 \mathrm{CR} 1)+$ macrophages in mice treated by cardiac stem cell or sterile antigen exposure after ischemia-reperfusion injury. The authors focused on acute sterile immune response characterized by transient and local tried induction of CCR2 + and CX3CR1+ positive macrophages.

The induction of CCR2+ and CX3CR1+ macrophages at the middle stage of ischemia-reperfusion injury (approximately 3 to 7 days) were induced not only by cell therapy but also by intracardiac injection of cells that have been killed by freeze-thaw or chemical inducers of the innate immune response.

After all, both cell therapy and inducers of the innate immune response resulted in functional rejuvenation - the formation of new cardiomyocytes (ie, pericentriolar material $1+)$ in the heart after ischemia-reperfusion injury. In these respects, the functional benefits of cardiac cell therapy have shown the potential for an acute inflammation-based wound healing response that rejuvenates the infarcted area of the heart.

In turn, CX3CR1-null mice did not benefit from bone marrow mononuclear cells (MNCs) therapy and showed a much larger total inflammatory response. CX3CR1 deficiency does not impair the contents of macrophages present in tissues, but affects the function of these macrophages and increases tissue inflammation. However, a significantly higher mortality rate after MI was observed in CX3CR1null mice. This suggests that CX3CR1 cells play a key role in late infarct maturation and remission. Injecting bone marrow MNCs around the ischemia-reperfusion injury area significantly reduced extracellular matrix content in the border area around the infarction. Certain subtypes of macrophages recruited by MNCs therapy differentially affect the passive mechanical properties of the MI area by influencing cardiac fibroblast activity. These results indicate an important functional distinction between CCR2 and CX3CR1 macrophages in cardiac wound healing.

On the other hand, there is another perspective has been associated with the early stage of wound healing (approximately 3 days) after MI inducing a loss of normal immunosuppressive mechanisms. A key player of immunosuppressive mechanisms are regulatory $\mathrm{T}$ lymphocytes (Tregs). Tregs are considered important suppressors of the immune response. In fact, CD4+ Foxp3 + Tregs strongly expanded in the heart, circulation, spleen, and lymph nodes after MI. An inducible Foxp3-null mouse, at age 8 to 10 weeks, with ischemic cardiomyopathy reverses about $10 \%$ of left ventricle remodeling and dysfunction 4 to 8 weeks after artificial MI. Left ventricle remodeling and dysfunction while suppressing circulating CD4+ T cells and systemic inflammation, promoting tissue angiogenesis and hypertrophy. ${ }^{16}$ Acute Treg dysfunction after ischemia-reperfusion injury was also closely associated with angiogenesis.

These aspects suggest that regulation of the innate immune response is important in practicing stem cell transplantation therapy. In addition, it is also understood that there are various factors to be verified in the process of healing an ischemic lesion. ${ }^{17}$

\section{ADVANTAGE OF PEDIATRIC CARDIAC STEM CELL THERAPY}

Human CDCs isolated from neonatal heart tissue have revealed a remarkable regenerative capability compared with those from adults in experimental MI, suggesting a possible contribution of CDCs in congenital cardiac repair. Direct comparison of CDCs between children and adults has shown that there might be a greater abundance of these cells within the heart of patients with congenital heart disease (CHD). ${ }^{18}$ Mishra and colleagues ${ }^{11}$ investigated the prevalence and proliferation capacity of different stem cell-like cells acquired from cardiac tissue of children 
undergoing open heart surgery. They showed that expression of c-kit was highest within the right atrium $(5.2 \%)$ compared with the ventricle $(1.4 \%)$. Also, c-kit expression was highest in neonates $(8.9 \%)$ and declined with advancing age in infants $(6.4 \%)$ and children $>2$ years of age $(3.2 \%)$. In addition, c-kit + human cardiac progenitor cells (hCPCs) were 3 times more frequently found in neonates than in children over age 2 years. The proliferation and differentiation potential of the hCPCs was also greater in neonates, as shown by the higher expression levels of ckit and Ki67, as well as the expression of NKX2, NOTCH1, and $N U M B$, the genes responsible for proliferation and differentiation. Furthermore, heart tissue samples of children with CHD contained an increased number of ckit + hCPCs, and CD133+ cells, and these cells expressed cardiac lineage and endothelial transcription factors during differentiation under in vitro conditions. ${ }^{19}$

There is more evidence that CPCs obtained from neonates are superior to those from adults in the recovery of cardiac function. ${ }^{20}$ The greater expression of heat shock factor-1 in neonatal CPCs may account for this superiority. Similarly, Agarwal and colleagues ${ }^{21}$ found that when studied in rats with MI the exosomes, lipid bilayer nanovesicles secreted by a variety of the cells when multivesicular endosomes fuse with the plasma membrane, obtained from CPCs of human neonates were superior to those from older children. These age-dependent functional characteristics of CPCs were further investigated by using c-kit- expressing CPCs. Transplantation of neonatal CPCs into rat infarcted heart tissue produced significantly greater functional recovery through increased neovascular formation and paracrine factors secretion when compared with that paracrine factors secretion when compared with that of adult heart-derived CPCs. Neonatal CPC-derived total conditioned media could recapitulate these beneficial effects but not in that of adult CPCs, suggesting neonatal $\mathrm{CPC}$ secretome may play an important role in these processes.

\section{CLINICAL TRIAL OF PEDIATRIC CARDIAC STEM CELL THERAPY}

The most common cause of late complications in these single ventricle (SV) physiology patients is $\mathrm{HF}$ and our aim of regenerative therapy in patients with SV is simply to increase healthy myocardium, particularly in hypoplastic left heart syndrome with right ventricle-dominant anatomy.

The first clinical and comparative study of stem cell therapy in patients with SV physiology were conducted in Okayama University as the phase I Transcoronary Infusion of Cardiac Progenitor Cells in Patients with SV Physiology (TICAP) and as the phase II Cardiac Progenitor Cell Infusion to Treat Univentricular Heart Disease (PERSEUS) trials. The TICAP trial was designed to evaluate the safety and feasibility of stem cell therapy for HF in children with hypoplastic left heart syndrome. ${ }^{22,23}$ In our protocol, right atrium tissue was obtained during stage II or stage III operation to isolate CDCs. The cells were cultured to reach a cell number of 30,000 per kilogram of body weight and then infused into the coronary artery by cardiac catheterization 4 to 5 weeks after the surgical procedure. The initial results at 18 months after injection of the CDCs reported no adverse events related to the therapy and a mean improvement in ejection fraction from $46.9 \%$ to $54.0 \%$ (vs a change of $46.7 \%$ to $48.7 \%$ in the control group). In addition, a significant improvement of growth was observed at 18 months, whereas there was no change in growth in the control group. The phase II study (PERSEUS) has been conducted since April 2013 after the encouraging results of the TICAP trial. ${ }^{24}$ In PERSEUS, we expanded the indication to patients with SV. A total of 34 patients were randomly assigned to the treatment or control group in a 1:1 ratio. The results of the PERSEUS trial suggest robust evidence that intracoronary infusion of autologous CDCs have a positive effect for cardiac function. At 3 months, the absolute changes in ventricular function were significantly greater in the CDC-treated group than in the controls $(+6.4 \%$ vs $+1.3 \%)$. These beneficial effects of CDCs implantation lead to a reduction of HF status; acceleration of somatic growth, which causes improvement of quality of life; and relief of parental stress. A retrospective cohort study to evaluate the therapeutic efficacy of CDCs infusion in patients with SV physiology at 2 years demonstrated that intracoronary delivery or CDCs significantly improved ventricular function and reduced the incidences of late failure, adverse events, and unplanned catheter intervention in patients with SV who underwent stage 2 or 3 palliation at 2 years of follow-up. ${ }^{25}$ An industry-sponsored, multicenter, randomized phase III clinical trial for SV (Cardiac Stem/ Progenitor Cell Infusionin Univentricular Physiology [APOLLON] trial; ClinicalTrials.gov identifier: NCT02781922) started in 2016 at 3 children's hospitals, including Okayama University, to verify the risk/benefit of intracoronary infusion of autologous CDCs in a large population.

There are additional 8 ongoing cell-based clinical trials for pediatric HF (Table 2). Out of these 8, 3 clinical trials are using autologous UCB-derived stem cells. Recently, Burkhart and colleagues ${ }^{26}$ reported the result of phase I clinical trial using autologous USB directly into the right ventricle myocardium of patients with hypoplastic left heart syndrome. They found that stem cell therapy using autologous USB is safe and feasible, although they found no improvement in cardiac function.

\section{FUTURE DIRECTIONS}

Although the functional benefits of cell therapy might be largely mediated by autocrine or paracrine factor secretion to repair the injured myocardium rather than de novo 
TABLE 2. Ongoing stem cell clinical trials for pediatric heart disease

\begin{tabular}{llllllll}
\hline Target diseases & $\begin{array}{c}\text { No. of } \\
\text { subjects }\end{array}$ & Cell type & $\begin{array}{c}\text { Delivery } \\
\text { method }\end{array}$ & Phase & Study location & Commencement & $\begin{array}{c}\text { ClinicalTrials.gov } \\
\text { NCT No. }\end{array}$ \\
\hline HLHS & 30 & UCB & IM & I & United States & May 2013 & NCT01883076 \\
HLHS & 12 & UCB & IC & I & Australia & February 2018 & NCT03431480 \\
\hline HLHS & 100 & UCB & IM & IIb & United States & April 2019 & NCT03779711 \\
HLHS & 24 & MSCs & IM & I/II & United States & November 2017 & NCT03079401 \\
HLHS & 30 & MSCs & IM & I/II & United States & February 2018 & NCT03525418 \\
HLHS & 30 & CSCs & IC & I & United States & November 2019 & NCT03406884 \\
$\begin{array}{l}\text { HLHS, Single } \\
\text { ventricle }\end{array}$ & 40 & CDCs & IC & III & Japan & June 2016 & NCT02781922 \\
DCM & 31 & CDCs & IC & I & Japan & April 2017 & NCT03129568 \\
\hline
\end{tabular}

NCT, National Clinical Trial; HLHS, hypoplastic left heart syndrome; UCB, umbilical cord blood; IM, intramuscular, IC, intracoronary, MSCs, mesenchymal stem cells; CSCs, cardiac stem cells; $C D C s$, cardiosphere derived stem cells; $D C M$, dilated cardiomyopathy.

myocardial differentiation in situ, the achieved consensus has shed light on proteins and noncoding RNAs transferred by stem cell-secreted exosomes to mediate the protective effects. The clinical efficacy of stem cell therapies in adult heart disease remains elusive, and the mechanisms underlying the regenerative processes in children are still unclear.

The advantage of the biological significance of resident CPCs from CHD should be taken into account for disease modeling and development of novel regenerative therapies. New insights into CPCs and mesenchymal stem cells isolated from pediatric patients, as well as molecular mechanisms controlling the cell proliferation and functional differentiation of these cells during stressed workload, may provide the foundation for exciting regenerative approaches for CHD treatments.

Many groups are currently investigating various avenues of stem cell optimization such as cell preconditioning using drugs or environmental stressors and genetic manipulations to increase angiogenesis, enhance survival pathways, and boost the promoters to differentiate into effective cardiomyocytes. The potential for optimizing stem cell therapy using preconditioning, genetic modification, or other ex vivo manipulated stem cells will significantly propel this type of therapy forward and provide invaluable information on stem cell biology. Due to several advantages of CDCs in neonates and infants, the best responders to cell therapy may indeed be children, especially neonates and infants.

\section{Conflict of Interest Statement}

The authors reported no conflicts of interest.

The Journal policy requires editors and reviewers to disclose conflicts of interest and to decline handling or reviewing manuscripts for which they may have a conflict of interest. The editors and reviewers of this article have no conflicts of interest.

\section{References}

1. Oh H, Ito H, Sano S. Challenges to success in heart failure: cardiac cell therapies in patients with heart diseases. J Cardiol. 2016;68:361-7.

2. Fisher SA, Doree C, Mathur A, Martin-Rendon E. Meta-analysis of cell therapy trials for patients with heart failure. Circ Res. 2015;116:1361-77.

3. Nguyen PK, Rhee JW, Wu JC. Adult stem cell therapy and heart failure, 2000 to 2016 a systematic review. JAMA Cardiol. 2016;1:831-41.

4. Gyöngyösi M, Haller PM, Blake DJ, Martin-Rendon E. Meta-analysis of cell therapy studies in heart failure and acute myocardial infarction. Circ Res. 2018;123:301-8.

5. Beltrami AP, Barlucchi L, Torella D, Baker M, Limana F, Chimenti S, et al. Adult cardiac stem cells are multipotent and support myocardial regeneration. Cell. 2003; $114: 763-76$.

6. Messina E, De Angelis L, Frati G, Morrone S, Chimenti S, Fiordaliso F, et al. Isolation and expansion of adult cardiac stem cells from human and murine heart. Circ Res. 2004;95:911-21.

7. Bolli R, Chugh AR, D’Amario D, Loughran JH, Stoddard MF, Ikram S, et al. Cardiac stem cells in patients with ischaemic cardiomyopathy (SCIPIO): initial results of a randomised phase 1 trial. Lancet. 2011;378:1847-57.

8. Makkar RR, Smith RR, Cheng K, Malliaras K, Thomson LE, Berman D, et al. Intracoronary cardiosphere-derived cells for heart regeneration after myocardial infarction (CADUCEUS): a prospective, randomized phase 1 trial. Lancet. 2012; 379:895-904.

9. Epstein JA. A time to press reset and regenerate cardiac stem cell biology. JAMA Cardiol. 2019;4:95-6.

10. Lemcke H, Voronina N, Steinhoff G, David R. Recent progress in stem cell modification for cardiac regeneration. Stem Cells Int. 2018;2018:1909346.

11. Mishra R, Vijayan K, Colletti EJ, Harrington DA, Matthiesen TS, Simpson D, et al. Characterization and functionality of cardiac progenitor cells in congenital heart patients. Circulation. 2011;123:364-73.

12. Orlic D, Kajstura J, Chimenti S, Jakoniuk I, Anderson SM, Li B, et al. Bone marrow cells regenerate infarcted myocardium. Nature. 2001;410:701-5.

13. Balsam LB, Wagers AJ, Christensen JL, Kofidis T, Weissman IL, Robbins RC Haematopoietic stem cells adopt mature hematopoietic fates in ischaemic myocardium. Nature. 2004;428:668-73.

14. Fadini GP, Losordo D, Dimmeler S. Critical reevaluation of endothelial progenitor cell phenotypes for therapeutic and diagnostic use. Circ Res. 2012;110: 624-37.

15. Vagnozzi RJ, Maillet M, Sargent MA, Khalil H, Johansen AKZ, et al. An acute immune response underlies the benefit of cardiac stem-cell therapy. Nature. 2020;577:405-9.

16. Bansal SS, Ismahil MA, Goel M, Zhou G, Rokosh G, Hamid T, et al. Dysfunc tional and pro-inflammatory regulatory T-lymphocytes are essential for adverse cardiac remodeling in ischemic cardiomyopathy. Circulation. 2019;139:206-21.

17. Epstein JA, Rosenthal N, Feldman AM. Teasing immune system to repair the heart. N Engl J Med. 2020;382:1660-2.

18. Tateishi K, Ashihara E, Honsho S, Takehara N, Nomura T, Takahashi T, et al. Human cardiac stem cells exhibit mesenchymal features and are maintained through Akt/GSK-3beta signaling. Biochem Biophys Res Commun. 2007;352:635-41. 
19. Ghazizadeh Z, Vahdat S, Fattahi F, Fonoudi H, Omrani G, Gholampour M, et al. Isolation and characterization of cardiogenic, stem-like cardiac precursors from heart samples of patients with congenital heart disease. Life Sci. 2015;137: $105-15$.

20. Sharma S, Mishra R, Bigham GE, Wehman B, Khan MM, Xu H, et al. A deep proteome analysis identifies the complete secretome as the functional unit of human cardiac progenitor cells. Circ Res. 2017;120:816-34.

21. Agarwal U, George A, Bhutani S, Ghosh-Choudhary S, Maxwell JT, Brown ME, et al. Experimental, systems, and computational approaches to understanding the microRNA-mediated reparative potential of cardiac progenitor cell-derived exosomes from pediatric patients. Circ Res. 2017;120:701-12.

22. Tarui S, Sano S, Oh H. Stem cell therapies in patients with single ventricle physiology. Methodist Debakey Cardiovasc J. 2014;10:77-81.

23. Ishigami S, Ohtsuki S, Tarui S, Ousaka D, Eitoku T, Kondo M, et al. Intracoronary autologous cardiac progenitor cell transfer in patients with hypoplastic left heart syndrome: the TICAP prospective phase 1 controlled trial. Circ Res. 2015; 116:653-64.
24. Ishigami S, Ohtsuki S, Eitoku T, Ousaka D, Kondo M, Kurita Y, et al. Intracoronary cardiac progenitor cells in single ventricle physiology: the PERSEUS (Cardiac Progenitor Cell Infusion to Treat Univentricular Heart Disease) randomized phase 2 trial. Circ Res. 2017;120:1162-73.

25. Sano T, Ousaka D, Goto T, Ishigami S, Hirai K, Kasahara S, et al. Impact of cardiac progenitor cells on heart failure and survival in single ventricle congenital heart disease. Circ Res. 2018;122:994-1005.

26. Burkhart HM, Qureshi MY, Rossano JW, Peral SC, O’Leary PW, Hathcock M et al. Autologous stem cell therapy for hypoplastic left heart syndrome: safety and feasibility of intraoperative intramyocardial injections. J Thorac Cardiovasc Surg. 2019;158:1614-23.

Key Words: cardiac stem cell therapy, cardiac progenitor cells, cardiosphere-derived cells, hypoplastic left heart syndrome, single ventricle 